\title{
Presentation of the Iberoamerican Journal of Science Measurement and Communication
}

Carlos Luis González-Valiente 1

González-Valiente, C.L. (2020).

Presentation of the Iberoamerican Journal of Science Measurement and Communication.

Iberoamerican Journal of Science Measurement and

Communication; 1(1),

1-3. https://doi.org/10.47909/

ijsmc.09

Received date: 28 September

2020

Accepted date: 10 October 2020

Handling editor: Nancy Sánchez Tarragó

\section{Copyright: @ 2020}

González-Valiente. This is an open terms of the CC BY-NC 4.0 license which permits copying and redistributing the material in any medium or format, adapting, transforming and building upon the material as long as the license terms are followed.
How to cite (APA): access article distributed under the

As part of the ecosystem of science production, understood to be a mega process, the stages of publication-communication of results, measurement, and analysis of publications, as well as evaluation of scientific policies, have become the object of considerable interest in the academic environment.

Science found its formal communication channel through the printed medium, mainly in the form of encyclopedias, books, and journals. However, since the first decades of the 19th Century, journals took an advantageous position with respect to encyclopedias and books, as scientific content began to be published much more quickly and regularly (Capurro, 2015). This generated exponential growth in the scientific literature, which was exacerbated by the considerable investments in science and technology from the Second World War. On the other hand, technological advances in the publishing industry, especially in the field of scholarly publishing, the university-business relationship, and the direct connection of science with society have led to the development of new areas of study and practice.

In the late 1960s, areas related to science communication emerged, such as public communication of science and technology, and public understanding of science (Rogers, 2001). The literature published in this regard was clear evidence of the growth of these study areas, through which a set of models, traditions, and approaches began to be defined by which a multifaceted space of knowledge was shaped (Logan, 2001). Further, "the citation indices developed by Eugene Garfield during the 1960s provided the sociology of science and bibliometrics with new measurement instruments for understanding social and epistemic aspects of science" (Bar-llan et al, 2018, p. 654).

As part of the activities and processes related to scientific publishing, issues such as the commercialization of academic publications, editorial technology, and the peer review process are explored (Fyfe et al., 2017). Other issues related in this matter are currently

1 European Alliance for Innovation, Slovakia. Email: carlos.valiente89@gmail.com 
very controversial and debated, such as (1) preprints and plagiarism, (2), the journal brand and its impact factor as measures of author quality, (3) the credibility of peer review, (4) the effectiveness of current peer review models, (5) predatory journals and their relationship to the Open Access Movement, (6) the copyright transfer of authors, (7) Open Access and Article Processing Charge (APC) model, (8) embargo and 'green' open access, (9) Web of Science and Scopus as platforms representing world scientific knowledge, and (10) the role of publishers in adding value to the academic communication process (Tennant et al. 2019). Many of these aspects also reflect geopolitical asymmetries in the production and circulation of knowledge, which mainly affect regions such as Latin America, Africa, and parts of Asia (Beigel, 2013).

These themes have been studied from various disciplines, giving rise to a noticeable coexistence of various traditions, schools of thought, and researchers. We are precisely in the presence of complex topics whose borders are diffuse, the views are multidisciplinary, and the variety of models, strategies, and methods to publish, communicate, and evaluate science still seem to be insufficient. In order to discuss these problems we have created the Iberoamerican Journal of Science Measurement and Communication (IJSMC); a journal that we seek to become a solid platform for synergies between quantitative aspects of science, the evaluation of research policies and systems, communication, and the sociology of science, from a multilingual and inclusive perspective, embracing diverse approaches and research methods.

The IJSMC highlights the Ibero-American term in its title to reinforce its purpose of promoting research produced in this region, however, it will not be restricted to this geographical context. That is why articles are accepted in Spanish, Portuguese, as well as English as the official language of publication. All articles are peer-reviewed and available in immediate open access at no cost to authors and readers. The authors preserve the copyrights to their works.

Researchers, academicians, students, and practitioners from various disciplines are invited to send articles that contribute to the development of these topics, as well as to share the contents of the journal. It is a privilege that the IJSMC has the support of the Postgraduate Program in Information Science of the Federal University of Santa Catarina, Brazil, as well as an editorial committee conformed of renowned international experts from various institutions, sectors, and countries. On behalf of this great team, I reiterate once again the welcome to this new journal.

\section{References}

Beigel, F. (2013). Centros y periferias en la circulación internacional del conocimiento. Nueva Sociedad, 245, 110-123. Retrieved from https://nuso.org/articulo/ centros-y-periferias-en-la-circulacion-internacional-del-conocimiento/

Capurro, R. (2015). ¿Qué es una revista científica?. Informatio. Revista del Instituto de Información de la Facultad de Información y Comunicación, 20(1), 3-24.

Rogers, C. L. (2001). Understanding Public Communication of Science and Technology. Science Communication, 23(2), 95-96. https://doi.org/10.1177\%2F1075547001023002001

Logan, R. A. (2001). Science mass communication: Its conceptual history. Science Communication, 23(2), 135-163. https://doi.org/10.1177\%2F1075547001023002004

Fyfe, A., Coate, K., Curry, S., Lawson, S., Moxham, N., \& Røstvik, C. M. (2017). Untangling 
academic publishing: A history of the relationship between commercial interests, academic prestige and the circulation of research. Recuperado de http://eprints.bbk.ac.uk/19148/

Tennant, J. P., Crane, H., Crick, T., Davila, J., Enkhbayar, A., Havemann, J., ... \& Rice, C. (2019). Ten hot topics around scholarly publishing. Publications, 7(2), 34. https://doi.org/ 10.3390/publications7020034

Bar-llan, J., Haustein, S., Milojević, S., Peters, I., \& Wolfram, D. (2018). Peer review, bibliometrics and altmetrics-Do we need them all?. Proceedings of the Association for Information Science and Technology, 55(1), 653-656. https://doi.org/10.1002/ pra2.2018.14505501073 